\title{
Biomarkers in Vestibular Schwannoma-Associated Hearing Loss
}

\author{
Luis Lassaletta ${ }^{1,2,3 *}$, Miryam Calvino ${ }^{1,2}$, Jose Manuel Morales-Puebla ${ }^{1}$, \\ Pablo Lapunzina ${ }^{2,3,4}$, Lourdes Rodriguez-de la Rosa ${ }^{2,3,5}$, Isabel Varela-Nieto ${ }^{2,3,5}$ and \\ Victor Martinez-Glez ${ }^{2,3,4}$
}

${ }^{1}$ Department of Otorhinolaryngology, La Paz University Hospital, Madrid, Spain, ${ }^{2}$ IdiPAZ Research Institute, Madrid, Spain, ${ }^{3}$ Centre for Biomedical Network Research on Rare Diseases (CIBERER), CIBER, Institute of Health Carlos III, Madrid, Spain, ${ }^{4}$ Institute of Medical and Molecular Genetics (INGEMM), La Paz University Hospital, Madrid, Spain, ${ }^{5}$ Institute for Biomedical Research "Alberto Sols" (IIBM), Spanish National Research Council-Autonomous University of Madrid (CSIC-UAM), Madrid, Spain

Vestibular schwannomas (VSs) are benign tumors composed of differentiated neoplastic Schwann cells. They can be classified into two groups: sporadic VS and those associated with neurofibromatosis type 2 (NF2). VSs usually grow slowly, initially causing unilateral sensorineural hearing loss $(\mathrm{HL})$ and tinnitus. These tumors cause $\mathrm{HL}$ both due to compression of the auditory nerve or the labyrinthine artery and due to the secretion of different substances potentially toxic to the inner ear or the cochlear nerve. As more and more patients are diagnosed and need to be managed, we are more than ever in need of searching for biomarkers associated with these tumors. Owing to an unknown toxic substance generated by the tumor, HL in VS may be linked to a high protein amount of perilymph. Previous studies have identified perilymph proteins correlated with tumor-associated $\mathrm{HL}$, including $\mu$-Crystallin (CRYM), low density lipoprotein receptor-related protein 2 (LRP2), immunoglobulin (lg) $\gamma$-4 chain C region, Ig $\kappa$-chain $\mathrm{C}$ region, complement $\mathrm{C} 3$, and immunoglobulin heavy constant $\gamma 3$. Besides, the presence of specific subtypes of heat shock protein 70 has been suggested to be associated with preservation of residual hearing. It has been recently demonstrated that chemokine receptor-4 (CXCR4) is overexpressed in sporadic VS as well as in NF2 tumors and that hearing disability and CXCR4 expression may be correlated. Further, the genetic profile of VS and its relationship with poor hearing has also been studied, including DNA methylation, deregulated genes, growth factors, and NF2 gene mutations. The knowledge of biomarkers associated with VS would be of significant value to maximize outcomes of hearing preservation in these patients.

Keywords: vestibular schwannoma, neurofibromatosis type 2, biomarkers, hearing loss, perilymph, chemokine, heat shock protein, genotype

\section{INTRODUCTION}

Vestibular schwannomas (VSs), previously termed acoustic neuromas, are non-malignant tumors composed of Schwann cells of the vestibulocochlear nerve (VIII cranial nerve), arising from either the internal auditory canal (IAC) or the cerebellopontine angle (CPA). They can be classified into two groups: sporadic VS and those associated with neurofibromatosis type 2 (NF2) (1). Most VSs 
are sporadic (90\%), with a combined lifetime risk of 1:1,000 for developing a unilateral tumor $(1,2)$. Nowadays, a higher rate of VS diagnosis has been described, due to incidental findings from magnetic resonance imaging (MRI) performed due to unrelated complaints (3).

The mortality rate of VS ranges from 0.2 to $1 \%$ (4). Due to their anatomic position, patients suffer from progressive hearing loss (90\%) and tinnitus (>60\%), with facial numbness (12\%) and facial paralysis (6\%) occurring mainly among patients with larger lesions. Balance dysfunction is often present, although $<20 \%$ of patients manifest with vertigo symptoms $(1,2)$. VSs usually grow slowly, leading to unilateral sensorineural hearing loss (SNHL) and tinnitus, theoretically caused by compression of the auditory nerve (3) or by spasm or occlusion of the labyrinthine artery (5). Sudden SNHL may also be the clinical presentation in up to $22 \%$ of the cases (6). These tumors may cause hearing loss also due to the secretion of substances potentially toxic to the inner ear or the cochlear nerve $(1,7,8)$.

Diagnosis of VS may be either from cranial MRI performed for unrelated complaints or, usually, due to unilateral hearing loss or tinnitus $(1,9)$.

Audiological tests including audiometry and auditory brainstem response are not reliable predictors of CPA pathology (10). As most patients with CPA tumors have a comparable set of symptoms and audiometric results, the diagnosis relies mainly on imaging. The gold standard for the diagnosis of VS is MRI with gadolinium (1). In the last years, improvements in technology and a higher accessibility to MRI have increased the number of diagnosed VSs (11).

Approximately three of each of the four VSs exhibit no growth, leading to an observation strategy (wait and scan). Mean growth is about 2-4 mm/year in growing tumors (12). The hearing status, the growth rate, the subject's age, and the surgeon's experience are the main factors when deciding between surgery (destructive or conservative) and gamma knife therapy

TABLE 1 | Proposed biomarkers of human VSs related to worse hearing.

\begin{tabular}{ll}
\hline CRYM & $\mu$-Crystallin \\
FN1 & Fibronectin 1 \\
KRT10 & Keratin 10 \\
APOC3 & Apolipoprotein C-III \\
VCAN & Versican \\
DCD & Dermcidin \\
SERPINB12 & Serpin family B member 12 \\
CTSD & Cathepsin D \\
SERPINB3 & Serpin family B member 3 \\
SERPINA5 & Serpin family A member 5 \\
SOD3 & Superoxide dismutase 3, extracellular \\
PARK7 & Parkinson disease protein 7 \\
SERPINF1 & Serpin family F member 1 \\
CHI3L1 & Cartilage glycoprotein 39 \\
LRP2 & Low-density lipoprotein receptor-related protein 2
\end{tabular}

Modified from Lysaght et al. (20).
(13). In recent years, gamma knife radiosurgery is becoming a more popular choice for subjects with growing small or medium tumors and useful hearing, while patients with large-size tumors usually undergo surgery (14).

As more and more patients are diagnosed and need to be managed, we are more than ever in need of searching for biomarkers associated with these tumors, in order to help with the choice of selecting between a "wait-and-scan" approach and surgery (15) aimed at reducing morbidity and increasing the hearing outcomes (4).

\section{BIOLOGICAL MARKERS}

Due to the lack of biopsy sampling without the destruction of the organ, little is known about the cellular and molecular correlates in inner ear pathology (16).

In recent years, considerable progress in proteomics has been enabled by modern technology. By a shotgun proteomics approach, the identification of proteins with high sensitivity is enabled (17). Mass spectrometric (MS) analyses have been successfully used for auditory proteomics and require a more concerted effort for biomarker identification (18). In addition, sophisticated methods for perilymph sampling (19) have revolutionized the field of otology, offering precious biofluid samples for analysis.

\section{Perilymph Proteome}

Perilymph, an extracellular fluid of the inner ear, is found within the scala tympani and vestibuli of the cochlea. During an apoptotic or necrotic episode inside the inner ear, the proteins that are secreted can be found at high concentrations in this fluid (20). The knowledge of the perilymph proteome may shed some light on the mechanisms of tumor-associated hearing loss, which are mostly unknown to date (15). Stankovic et al. speculated that because of an unknown toxic substance generated by the VS, hearing loss in VS could be linked to a high protein concentration in the perilymph (7).

\section{Perilymph Proteins Related to Hearing Loss}

In 2011, Lysaght et al. identified 15 proteins from perilymph specimens (selected by comparing VS and cochlear implant samples) with differential expression and biological function. They suggested the use of this list in future research focused on distinguishing between better vs. worse hearing in patients with VS (see Table 1) (20).

$\mu$-Crystallin (CRYM) or nicotinamide adenine dinucleotide phosphate (NADPH)-regulated thyroid hormone binding protein is located within the cytoplasm, where it promotes transcription of the thyroid hormone triiodothyronine (T3) (20, 21). CRYM gene mutations cause autosomal-dominant hearing loss due to changes in the intracellular localization and the inability to bind to T3, which may lead to an altered $\mathrm{K}+$ recycling $(20,22)$.

Low density lipoprotein receptor-related protein 2 (LRP2) or megalin is a trans-membrane receptor protein, which can be found in certain epithelial cells such as those of the ear. LRP2 has the ability to bind several ligands, being essential in the 
process of endocytosis of different elements such as sterols, lipoproteins, hormones, and vitamin binding proteins. Two wellknown conditions, Donnai-Barrow and facio-oculo-acousticorenal (FOAR) syndromes (23), both associated with SNHL, are the result of mutations in the LRP2 gene (20).

On the other hand, of the 91 commonly identified perilymph proteins of patients with VS on an individual level, Rasmussen et al. described four proteins that were significantly associated with tumor-related deafness: Immunoglobulin (Ig) $\gamma$ 4 chain $\mathrm{C}$ region, $\mathrm{Ig} \kappa$ chain $\mathrm{C}$ region, complement $\mathrm{C} 3$, and immunoglobulin heavy constant $\gamma 3$. These 91 proteins were identified in 12 out of 15 samples they used in the study (15), which was confirmed by analogy with data from previous MS research on perilymph $(20,24)$.

Moreover, alpha-2-HS-glycoprotein, a suggested inflammatory and immunological intermediary in perilymph, was suggested to be associated with deafness in patients with SVs. It was also discovered in samples from VS patients in 2017 (24), and although its concentration was not directly linked to the hearing outcomes, the authors attempted to further investigate this potential association. Rasmussen et al. hypothesized that VS may excrete alpha-2-HS-glycoprotein to the perilymph, where its inflammatory activity may lead to SNHL. Factors elicited from the VS may also affect the inner ear, inducing an upregulation of alpha-2-HS-glycoprotein within the perilymph (15).

\section{Heat Shock Proteins and Hearing Loss}

Heat shock proteins (HSPs) are stress proteins, which mediate cell survival under critical environmental conditions (25). Increased perilymph levels of 10 different subgroups of HSP were detected in subjects undergoing cochlear implantation that preserved hearing when compared with those without hearing preservation, and cochlear transcriptome data suggest that there is a baseline protective expression of HSP70 1A, 1B, 2, 4, 5, 6, 8, 9, and 12A mRNA (16).

HSP90 is the most important chaperone for cellular stress. It is involved in pathological processes, such as cancer development (26), and its increased expression as a stress responsive biomarker is present in multiple types of tissue inflammation (27).

Recently, Schmitt et al. found that HSP90 was determined in the perilymph of half of the patients $(n=18)$ experiencing complete loss of residual hearing loss after cochlear implantation, whereas only one of the patients with preserved residual hearing showed HSP90 in perilymph. The upregulation of HSP90 in the perilymph may therefore induce the migration of macrophages and leukocytes, resulting in cochlear inflammation. However, despite the cellular changes observed, the authors could not detect a significant difference in HSP90 expression in patients with VS compared with patients without tumor (16).

On the other hand, HSP70 has been identified as an otoprotective agent and protects hair cells from stress-induced apoptosis (28). Interestingly, the presence of some subtypes of HSP70 seemed to correlate with preservation of residual hearing in cochlear implantation (16). It has been associated with an increase in the cell proliferation rate (29) and, according to Schmitt et al., could take part in the development of VS, despite the authors not finding any correlation between HSP70 expression and VS when comparing with subjects without tumor (16). One explanation could be the low proliferation rate of these tumors; by contrast, medulloblastomas, fast-proliferating intracranial tumors with poor prognosis, showed an increased expression of HSP70 (29).

According to these findings, more data on the regulation of these proteins and perilymph proteomics are mandatory to demonstrate the role of these HSPs in patients with VS and hearing loss.

\section{Increased Concentration of Perilymphatic Proteins and MRI Findings}

Increased signal intensity of the fluid on three-dimensional fluid-attenuated inversion recovery (3D-FLAIR) MRI has been reported in various diseases, including SNHL, and VS (30-33). An increased concentration of proteins in the perilymphatic space has been proposed to explain the enhanced cochlear signal on FLAIR images in subjects with VS (34-37).

Kim et al. demonstrated a correlation between a higher cochlear signal on 3D FLAIR images and hearing loss in patients with VS (38). The correlation was stronger in intrameatal tumors when compared to all subjects, and no correlation was found when considering only CPA tumors. Interestingly, the cochlear signal intensity on MRI was significantly higher in tumors confined to the IAC.

\section{Endolymphatic Hydrops}

Ipsilateral inner ear alterations, including endolymphatic hydrops (EH) and acidophilic-staining precipitate, have been observed in temporal bone histopathological studies from patients with VS $(5,39)$. In the past years, intratympanic gadolinium injection has arisen as a new tool in the diagnosis of EH (40). Recently, delayed intravenous gadolinium-enhanced high-resolution MRI of the inner ear has been shown to provide resolution adequate for accurate detection of $\mathrm{EH}(41,42)$. In addition, heavily weighted T2 sequences are useful to evaluate the cochlear fluids in patients with VS. In patients with a tumor entirely blocking the IAC, the volume of the vestibular endolymphatic space can be determined with great certainty. Venkatasamy et al. described a difference in the perilymphatic signal on a T2-weighted steady state free precession acquisition at $3 \mathrm{~T}$, providing a new tool for differentiating schwannomas and meningiomas (43). In patients with VS, a correlation between the endolymphatic space volume and the level of hearing loss has been described. Eliezer et al., using a 3D non-contrast $\mathrm{T} 2$ heavily weighted sequence at $3 \mathrm{~T}$, showed that the utricle volume was correlated with the patient's hearing loss in a series of 23 VSs. As most subjects with VS benefit from a wait-andscan strategy, based on these MRI results, they suggest that a treatment leading to decreased $\mathrm{EH}$ could be administrated to achieve better hearing outcomes (44). In a recent paper (45), a saccular dilatation on the ipsilateral side was demonstrated in $30 \%$ of VSs (53 out of 183 patients with typical VS). In this study, a 3D non-contrast high-resolution T2-weighted sequence was used. 


\section{Tissue Sample Proteins Cytokines and Hearing Loss}

A large number of cytokines are produced by tumors (46) including VSs. To maintain the homeostasis in the cochlea, the cytokine balance is of vital importance (47). Like other substances, cytokines have been suggested to play a role in the labyrinth of degenerative changes (5). However, few studies have examined the role of these proteins in VS $(48,49)$.

Chemokine receptor-4 (CXCR4) is implicated in several pathological processes, including autoimmune disease, infection, and tumor development $(50,51)$. CXCR4 is overexpressed in many neoplasms, being capable of increasing tumor growth and invasiveness $(52,53)$.

C-X-C Motif Chemokine Ligand 12 (CXCL12), a ligand for CXCR4, cooperates with metastatic cells to CXCL12-expressing organs. The Ras/Raf/MEK and the PI3K/Akt/mTOR pathways can be activated by CXCL12 binding to the CXCR4 receptor. In a similar way, the loss of Merlin $(52,53)$, a tumor suppressor protein encoded by the NF2 gene in VS (54), leads to activation of these two primary pathways.

Recently, Breun et al. have described that CXCR4 could play a role in the pathogenesis of both sporadic and NF2-associated VS. In their study CXCR4 was overexpressed in these tumors, with no significant differences found between the two groups. CXCR4 mRNA expression increased with the degree of hearing loss when compared with the control group, with the results lacking statistical difference (53).

Although tumor extension may be related to hearing impairment in VS (55), there is usually a discrepancy between tumor size and hearing disability (9). A reason why hearing disability is not always correlated with tumor dimensions could be an invasive growth pattern caused by CXCR4 overexpression in certain tumors. Indeed, Breun et al. detected no correlation between CXCR4 expression and tumor extension; therefore, this chemokine receptor may be significant for tumor invasiveness, as exhibited by hearing disability (53).

\section{Molecular Biology}

According to Celis-Aguilar et al.'s review (8), the molecular biology of VS could been explained by several pathogenic mechanisms including chromosome 22 loss, NF2 gene mitotic recombination (56), DNA methylation (57), deregulation of genes (58), immunogenic factors (59), cytokines, and growth factors (60-62), and NF2 gene mutation (63).

\section{DNA Methylation}

Epigenetic alterations are found across many solid cancers, and although most efforts in VS are limited to the controversial DNA methylation of the NF2 gene, other changes have shown to play an important role in VS. Lassaletta et al. investigated the methylation status of 16 genes in 22 sporadic VSs and related it to clinical and radiological findings (57), the connection observed between TP73 aberrant methylation and deafness being important [Pure Tone Average (PTA) $=43$ and $17 \mathrm{~dB}$ for patients with methylated and unmethylated TP73 genes, respectively]. A genome-wide methylation analysis in VS also showed a trend toward hypomethylation in several miRNAs and coding genes, including alternative transcripts, opening a window to possible therapeutic targets (64).

\section{Deregulated Genes}

In a study searching for associations between the molecular basis of VS and hearing loss (7), surgical specimens of these tumors from 13 patients were classified into two groups based on gene expression, one with good hearing (word recognition $>70 \%$ and PTA $\leq 30 \mathrm{~dB}$ ) and another with poor hearing. PEX5L, RAD54B, the prostate-specific membrane antigen-like gene, and PSMAL had low expression in VS patients with bad hearing outcomes. Besides, the CEA-CAM7 gene and Carcinoembryonic Antigen (CEA) protein were overexpressed in VS patients with poor hearing (8).

\section{Growth Factors}

The development of VS has also been associated with abnormal expression of growth factors. In a study of tumor samples from 11 subjects with VS, Lassaletta et al. described an inverse correlation between the expression of platelet-derived growth factor A and deafness (65). On the other hand, vascular endothelial growth factors (VEGFs) have been associated with the hearing status of patients with VSs $(66,67)$. Most VSs express VEGF, and it has been suggested that this growth factor may play a role in both tumor growth and hearing status $(68,69)$. Bevacizumab, a VEGF neutralizing antibody, was used by Plotkin et al. to treat patients with VS, an increase in hearing reported in four out of seven subjects treated with this drug (67). In recent years, bevacizumab has been reported to increase speech understanding and hearing quality in several NF2 patients $(68,70)$.

\section{NF2 Gene Mutation}

NF2 gene mutations have been associated with the hearing level of patients with VS. In the study of Lassaletta et al., 51 cases undergoing surgery for VS were analyzed. Patients with NF2 gene mutations presented lower PTA thresholds compared with nonmutated cases (71).

Selvanathan et a1. analyzed the impact of age of onset on the existence of several NF2-related symptoms, including hearing impairment or tinnitus, and found that there was a significantly younger age of onset of symptoms in patients with nonsense or frameshift mutation (i.e., mutations that produce protein truncation). They hypothesized that a younger age of onset of VS could explain the younger age of onset of hearing loss (and tinnitus) (72).

Halliday et al. proposed a genetic severity score (1, tissue mosaic; $2 \mathrm{~A}$, mild classic; $2 \mathrm{~B}$, moderate classic; and 3, severe) in order to predict morbidity for NF2 subjects in certain dimensions including hearing status (73). According to Emmanouil et al., if subjects were stratified according to genetic severity, it could help to obtain a better prognostication of the hearing decline. In their study, they described a significant difference in terms of hearing decline according to the genetic severity: the median age for subjects rated as "severe" was 32 years, compared to a median of 80 years for patients classified as "tissue mosaic" (74). 


\section{CONCLUSION}

So far, no reliable methods are able to predict the evolution of hearing loss in subjects with VS. Several markers such as perilymph proteins have been associated with tumor hearing loss. Also, specific subtypes of HSP70 have been correlated with hearing outcomes. Cytokines produced by VS, especially CXCR4 expression, have been related to hearing impairment. DNA methylation, deregulated genes, growth factors, and NF2 gene mutation have also been related to hearing loss in subjects with VS. Most of these potential markers of hearing loss are not routinely available for the clinician. On the other hand, recent findings on imaging, especially delayed intravenous gadoliniumenhanced high-resolution MRI, and 3D non-contrast heavily T2-weighted sequences are promising in terms of therapeutic

\section{REFERENCES}

1. Kaul V, Cosetti MK. Management of vestibular schwannoma (including NF2): facial nerve considerations. Otolaryngol Clin North Am. (2018) 51:1193-212. doi: 10.1016/j.otc.2018.07.015

2. Schmidt RF, Boghani Z, Choudhry OJ, Eloy JA, Jyung RW, Liu JK. Incidental vestibular schwannomas: a review of prevalence, growth rate, and management challenges. Neurosurg Focus. (2012) 33:E4. doi: $10.3171 / 2012.7$. Focus 12186

3. Halliday J, Rutherford SA, McCabe MG, Evans DG. An update on the diagnosis and treatment of vestibular schwannoma. Expert Rev Neurother. (2018) 18:29-39. doi: 10.1080/14737175.2018.1399795

4. Sughrue ME, Yang I, Aranda D, Rutkowski MJ, Fang S, Cheung SW, et al. Beyond audiofacial morbidity after vestibular schwannoma surgery. $J$ Neurosurg. (2011) 114:367-74. doi: 10.3171/2009.10.Jns091203

5. Roosli C, Linthicum FH Jr, Cureoglu S, Merchant SN. Dysfunction of the cochlea contributing to hearing loss in acoustic neuromas: an underappreciated entity. Otol Neurotol. (2012) 33:473-80. doi: 10.1097/MAO.0b013e318248ee02

6. Fujita T, Saito K, Kashiwagi N, Sato M, Seo T, Doi K. The prevalence of vestibular schwannoma among patients treated as sudden sensorineural hearing loss. Auris Nasus Larynx. (2018) 46:78-82. doi: 10.1016/j.anl.2018.06.008

7. Stankovic KM, Mrugala MM, Martuza RL, Silver M, Betensky RA, Nadol JB Jr, et al. Genetic determinants of hearing loss associated with vestibular schwannomas. Otol Neurotol. (2009) 30:661-7. doi: 10.1097/MAO.0b013e3181a66ece

8. Celis-Aguilar E, Lassaletta L, Torres-Martin M, Rodrigues FY, Nistal M, Castresana JS, et al. The molecular biology of vestibular schwannomas and its association with hearing loss: a review. Genet Res Int. (2012) 2012:856157. doi: 10.1155/2012/856157

9. Lassaletta L, Gavilan J. An update on the treatment of vestibular schwannoma. Acta Otorrinolaringol Esp. (2009) 60:131-40. doi: 10.1016/S2173-5735(09)70116-4

10. Tutar H, Duzlu M, Goksu N, Ustun S, Bayazit Y. Audiological correlates of tumor parameters in acoustic neuromas. Eur Arch Otorhinolaryngol. (2013) 270:437-41. doi: 10.1007/s00405-012-1954-2

11. Stangerup SE, Caye-Thomasen P. Epidemiology and natural history of vestibular schwannomas. Otolaryngol Clin North Am. (2012) 45:257-68, vii. doi: 10.1016/j.otc.2011.12.008

12. Nikolopoulos TP, Fortnum H, O’Donoghue G, Baguley D. Acoustic neuroma growth: a systematic review of the evidence. Otol Neurotol. (2010) 31:478-85. doi: 10.1097/MAO.0b013e3181d279a3

13. Pinna MH, Bento RF, Neto RV. Vestibular schwannoma: 825 cases from a 25-year experience. Int Arch Otorhinolaryngol. (2012) 16:466-75. doi: $10.7162 /$ s1809-97772012000400007 management of patients with VS showing signs of EH. The precise knowledge of biomarkers associated with hearing loss in patients with VS would be useful to minimize morbidity and to maximize outcomes of hearing in these patients.

\section{AUTHOR CONTRIBUTIONS}

All authors listed have made a substantial, direct and intellectual contribution to the work, and approved it for publication.

\section{FUNDING}

This work was supported by a FEDER/Ministerio de Economía y Competitividad grant (SAF2017-86107-R) and by a Comunidad Autónoma de Madrid grant (B2017/BMD-3688).

14. Boari N, Bailo M, Gagliardi F, Franzin A, Gemma M, del Vecchio A, et al. Gamma Knife radiosurgery for vestibular schwannoma: clinical results at long-term follow-up in a series of 379 patients. J Neurosurg. (2014) 121(Suppl):123-42. doi: 10.3171/2014.8.Gks141506

15. Rasmussen JE, Laurell G, Rask-Andersen H, Bergquist J, Eriksson PO. The proteome of perilymph in patients with vestibular schwannoma. A possibility to identify biomarkers for tumor associated hearing loss? PLoS ONE. (2018) 13:e0198442. doi: 10.1371/journal.pone.0198442

16. Schmitt H, Roemer A, Zeilinger C, Salcher R, Durisin M, Staecker $\mathrm{H}$, et al. Heat shock proteins in human perilymph: implications for cochlear implantation. Otol Neurotol. (2018) 39:37-44. doi: $10.1097 /$ mao.0000000000001625

17. Darville LN, Sokolowski BH. In-depth proteomic analysis of mouse cochlear sensory epithelium by mass spectrometry. J Proteome Res. (2013) 12:3620-30. doi: $10.1021 / \mathrm{pr} 4001338$

18. Alawieh A, Mondello S, Kobeissy F, Shibbani K, Bassim M. Proteomics studies in inner ear disorders: pathophysiology and biomarkers. Expert Rev Proteomics. (2015) 12:185-96. doi: 10.1586/14789450.2015.10 24228

19. Salt AN, Hale SA, Plonkte SK. Perilymph sampling from the cochlear apex: a reliable method to obtain higher purity perilymph samples from scala tympani. J Neurosci Methods. (2006) 153:121-9. doi: 10.1016/j.jneumeth.2005.10.008

20. Lysaght AC, Kao SY, Paulo JA, Merchant SN, Steen H, Stankovic KM. Proteome of human perilymph. J Proteome Res. (2011) 10:3845-51. doi: $10.1021 / p r 200346 q$

21. Mori J, Suzuki S, Kobayashi M, Inagaki T, Komatsu A, Takeda T, et al. Nicotinamide adenine dinucleotide phosphate-dependent cytosolic $\mathrm{T}$ (3) binding protein as a regulator for $\mathrm{T}(3)$-mediated transactivation. Endocrinology. (2002) 143:1538-44. doi: 10.1210/endo.143.4.8736

22. Oshima A, Suzuki S, Takumi Y, Hashizume K, Abe S, Usami S. CRYM mutations cause deafness through thyroid hormone binding properties in the fibrocytes of the cochlea. J Med Genet. (2006) 43:e25. doi: 10.1136/jmg.2005.034397

23. Kantarci S, Al-Gazali L, Hill RS, Donnai D, Black GC, Bieth E, et al. Mutations in LRP2, which encodes the multiligand receptor megalin, cause Donnai-Barrow and facio-oculo-acoustico-renal syndromes. Nat Genet. (2007) 39:957-9. doi: 10.1038/ng2063

24. Schmitt HA, Pich A, Schroder A, Scheper V, Lilli G, Reuter G, et al. Proteome analysis of human perilymph using an intraoperative sampling method. $J$ Proteome Res. (2017) 16:1911-23. doi: 10.1021/acs.jproteome.6b00986

25. Taldone T, Ochiana SO, Patel PD, Chiosis G. Selective targeting of the stress chaperome as a therapeutic strategy. Trends Pharmacol Sci. (2014) 35:592603. doi: 10.1016/j.tips.2014.09.001

26. Haase M, Fitze G. HSP90AB1: helping the good and the bad. Gene. (2016) 575:171-86. doi: 10.1016/j.gene.2015.08.063 
27. Poulaki V, Iliaki E, Mitsiades N, Mitsiades CS, Paulus YN, Bula DV, et al. Inhibition of Hsp90 attenuates inflammation in endotoxin-induced uveitis. Faseb J. (2007) 21:2113-23. doi: 10.1096/fj.06-7637com

28. Takada Y, Takada T, Lee MY, Swiderski DL, Kabara LL, Dolan DF, et al. Ototoxicity-induced loss of hearing and inner hair cells is attenuated by HSP70 gene transfer. Mol Ther Methods Clin Dev. (2015) 2:15019. doi: $10.1038 / \mathrm{mtm} .2015 .19$

29. Alexiou GA, Vartholomatos G, Stefanaki K, Patereli A, Dova L, Karamoutsios A, et al. Expression of heat shock proteins in medulloblastoma. J Neurosurg Pediatr. (2013) 12:452-7. doi: 10.3171/2013.7.Peds1376

30. Bhadelia RA, Tedesco KL, Hwang S, Erbay SH, Lee PH, Shao W, et al. Increased cochlear fluid-attenuated inversion recovery signal in patients with vestibular schwannoma. AJNR Am J Neuroradiol. (2008) 29:720-3. doi: 10.3174/ajnr.A0968

31. Lee IH, Kim HJ, Chung WH, Kim E, Moon JW, Kim ST, et al. Signal intensity change of the labyrinth in patients with surgically confirmed or radiologically diagnosed vestibular schwannoma on isotropic 3D fluidattenuated inversion recovery MR imaging at 3 T. Eur Radiol. (2010) 20:94957. doi: 10.1007/s00330-009-1626-9

32. Yamazaki M, Naganawa S, Kawai H, Nihashi T, Fukatsu H, Nakashima T. Increased signal intensity of the cochlea on pre- and post-contrast enhanced 3D-FLAIR in patients with vestibular schwannoma. Neuroradiology. (2009) 51:855-63. doi: 10.1007/s00234-009-0588-6

33. Yoshida T, Sugiura M, Naganawa S, Teranishi M, Nakata S, Nakashima T. Three-dimensional fluid-attenuated inversion recovery magnetic resonance imaging findings and prognosis in sudden sensorineural hearing loss. Laryngoscope. (2008) 118:1433-7. doi: 10.1097/MLG.0b013e31817 2ef85

34. Palva T, Raunio V. Cerebrospinal fluid and acoustic neurinoma specific proteins in perilymph93:201-3. Acta Otolaryngol. (1982) 93:201-3.

35. Rasmussen N, Bendtzen K, Thomsen J, Tos M. Antigenicity and protein content of perilymph in acoustic neuroma patients. Acta Otolaryngol. (1984) 97:502-8.

36. Silverstein H. Labyrinthine tap as a diagnostic test for acoustic neurinoma. Otolaryngol Clin North Am. (1973) 6:229-44.

37. Thomsen J, Saxtrup O, Tos M. Quantitated determination of proteins in perilymph in patients with acoustic neuromas. ORL J Otorhinolaryngol Relat Spec. (1982) 44:61-5. doi: 10.1159/000275574

38. Kim DY, Lee JH, Goh MJ, Sung YS, Choi YJ, Yoon RG, et al. Clinical significance of an increased cochlear 3D fluid-attenuated inversion recovery signal intensity on an MR imaging examination in patients with acoustic neuroma. AJNR Am J Neuroradiol. (2014) 35:1825-9. doi: 10.3174/ajnr.A3936

39. Hizli O, Cureoglu S, Kaya S, Schachern PA, Paparella MM, Adams ME. Quantitative vestibular labyrinthine otopathology in temporal bones with vestibular schwannoma. Otolaryngol Head Neck Surg. (2016) 154:150-6. doi: $10.1177 / 0194599815601070$

40. Le CH, Truong AQ, Diaz RC. Novel techniques for the diagnosis of Meniere's disease. Curr Opin Otolaryngol Head Neck Surg. (2013) 21:492-6. doi: 10.1097/MOO.0b013e328364869b

41. Bernaerts A, Vanspauwen R, Blaivie C, van Dinther J, Zarowski A, Wuyts $\mathrm{FL}$, et al. The value of four stage vestibular hydrops grading and asymmetric perilymphatic enhancement in the diagnosis of Meniere's disease on MRI. Neuroradiology. (2019) 61:421-9. doi: 10.1007/s00234-019-02155-7

42. Moayer R, Ishiyama GP, Karnezis S, Sepahdari AR, Ishiyama A. High resolution three-dimensional delayed contrast MRI detects endolymphatic hydrops in patients with vertigo and vestibular schwannoma. Otol Neurotol. (2018) 39:e39-44. doi: 10.1097/mao.0000000000001627

43. Venkatasamy A, Le Foll D, Karol A, Lhermitte B, Charpiot A, Debry C, et al. Differentiation of vestibular schwannomas from meningiomas of the internal auditory canal using perilymphatic signal evaluation on T2-weighted gradient-echo fast imaging employing steady state acquisition at 3T. Eur Radiol Exp. (2017) 1:8. doi: 10.1186/s41747-017-0012-7

44. Eliezer M, Poillon G, Maquet C, Gillibert A, Horion J, Marie JP, et al. Sensorineural hearing loss in patients with vestibular schwannoma correlates with the presence of utricular hydrops as diagnosed on heavily T2-weighted MRI. Diagn Interv Imaging. (2019) 100:259-68. doi: 10.1016/j.diii.2019.01.006

45. Karch-Georges A, Veillon F, Vuong H, Rohmer D, Karol A, Charpiot A, et al. MRI of endolymphatic hydrops in patients with vestibular schwannomas: a case-controlled study using non-enhanced T2-weighted images at 3 Teslas. Eur Arch Otorhinolaryngol. (2019) 276:1591-9. doi: 10.1007/s00405-019-05395-8

46. Lin WW, Karin M. A cytokine-mediated link between innate immunity, inflammation, and cancer. J Clin Invest. (2007) 117:1175-83. doi: $10.1172 /$ jci31537

47. Adams JC. Clinical implications of inflammatory cytokines in the cochlea: a technical note. Otol Neurotol. (2002) 23:316-22. doi: 10.1097/00129492-200205000-00015

48. Hattermann K, Li G, Hugo HH, Mentlein R, Mehdorn HM, Held-Feindt J. Expression of the chemokines CXCL12 and CX3CL1 and their receptors in human nerve sheath tumors. Histol Histopathol. (2013) 28:1337-49. doi: $10.14670 / \mathrm{hh}-28.1337$

49. Held-Feindt J, Rehmke B, Mentlein R, Hattermann K, Knerlich F, Hugo $\mathrm{HH}$, et al. Overexpression of CXCL16 and its receptor CXCR6/Bonzo promotes growth of human schwannomas. Glia. (2008) 56:764-74. doi: 10.1002/glia.20651

50. Pozzobon T, Goldoni G, Viola A, Molon B. CXCR4 signaling in health and disease. Immunol Lett. (2016) 177:6-15. doi: 10.1016/j.imlet.2016.06.006

51. Bar-Shavit R, Maoz M, Kancharla A, Nag JK, Agranovich D, GrisaruGranovsky S, et al. G protein-coupled receptors in cancer. Int J Mol Sci. (2016) 17:1320. doi: 10.3390/ijms17081320

52. Domanska UM, Kruizinga RC, Nagengast WB, Timmer-Bosscha H, Huls G, de Vries EG, et al. A review on CXCR4/CXCL12 axis in oncology: no place to hide. Eur J Cancer. (2013) 49:219-30. doi: 10.1016/j.ejca.2012.05.005

53. Breun M, Schwerdtfeger A, Martellotta DD, Kessler AF, Perez JM, Monoranu CM, et al. CXCR4: a new player in vestibular schwannoma pathogenesis. Oncotarget. (2018) 9:9940-50. doi: 10.18632/oncotarget.24119

54. Lim SH, Ardern-Holmes S, McCowage G, de Souza P. Systemic therapy in neurofibromatosis type 2. Cancer Treat Rev. (2014) 40:857-61. doi: 10.1016/j.ctrv.2014.05.004

55. Samii M, Matthies C. Management of 1000 vestibular schwannomas (acoustic neuromas): hearing function in 1000 tumor resections. Neurosurgery. (1997) 40:248-60; discussion 60-2.

56. Hadfield KD, Smith MJ, Urquhart JE, Wallace AJ, Bowers NL, King AT, et al. Rates of loss of heterozygosity and mitotic recombination in NF2 schwannomas, sporadic vestibular schwannomas and schwannomatosis schwannomas. Oncogene. (2010) 29:6216-21. doi: 10.1038/onc.2010.363

57. Lassaletta L, Bello MJ, Del Rio L, Alfonso C, Roda JM, Rey JA, et al. DNA methylation of multiple genes in vestibular schwannoma: relationship with clinical and radiological findings. Otol Neurotol. (2006) 27:1180-5. doi: 10.1097/01.mao.0000226291.42165.22

58. Caye-Thomasen P, Borup R, Stangerup SE, Thomsen J, Nielsen FC. Deregulated genes in sporadic vestibular schwannomas. Otol Neurotol. (2010) 31:256-66. doi: 10.1097/MAO.0b013e3181be6478

59. Archibald DJ, Neff BA, Voss SG, Splinter PL, Driscoll CL, Link MJ, et al. B7H1 expression in vestibular schwannomas. Otol Neurotol. (2010) 31:991-7. doi: 10.1097/MAO.0b013e3181e40e4f

60. Niemczyk K, Vaneecloo FM, Lecomte MH, Lejeune JP, Lemaitre L, Skarzynski $\mathrm{H}$, et al. Correlation between Ki-67 index and some clinical aspects of acoustic neuromas (vestibular schwannomas). Otolaryngol Head Neck Surg. (2000) 123:779-83. doi: $10.1067 / \mathrm{mhn} .2000 .111356$

61. Blair KJ, Kiang A, Wang-Rodriguez J, Yu MA, Doherty JK, Ongkeko WM. EGF and bFGF promote invasion that is modulated by PI3/Akt kinase and Erk in vestibular schwannoma. Otol Neurotol. (2011) 32:308-14. doi: 10.1097/MAO.0b013e318206fc3d

62. O'Reilly BF, Kishore A, Crowther JA, Smith C. Correlation of growth factor receptor expression with clinical growth in vestibular schwannomas. Otol Neurotol. (2004) 25:791-6. doi: 10.1097/00129492-200409000-00024

63. Martinez-Glez V, Franco-Hernandez C, Alvarez L, De Campos JM, Isla A, Vaquero J, et al. Meningiomas and schwannomas: molecular subgroup classification found by expression arrays. Int J Oncol. (2009) 34:493-504. doi: $10.3892 /$ ijo_00000174

64. Torres-Martin M, Lassaletta L, de Campos JM, Isla A, Pinto GR, Burbano $\mathrm{RR}$, et al. Genome-wide methylation analysis in vestibular schwannomas shows putative mechanisms of gene expression modulation and global hypomethylation at the HOX gene cluster. Genes Chromosomes Cancer. (2015) 54:197-209. doi: 10.1002/gcc.22232 
65. Lassaletta L, Martinez-Glez V, Torres-Martin M, Rey JA, Gavilan J. cDNA microarray expression profile in vestibular schwannoma: correlation with clinical and radiological features. Cancer Genet Cytogenet. (2009) 194:125-7. doi: 10.1016/j.cancergencyto.2009.06.016

66. Koutsimpelas D, Stripf T, Heinrich UR, Mann WJ, Brieger J. Expression of vascular endothelial growth factor and basic fibroblast growth factor in sporadic vestibular schwannomas correlates to growth characteristics. Otol Neurotol. (2007) 28:1094-9. doi: 10.1097/MAO.0b013e31814b2787

67. Plotkin SR, Stemmer-Rachamimov AO, Barker FG 2nd, Halpin C, Padera TP, Tyrrell A, et al. Hearing improvement after bevacizumab in patients with neurofibromatosis type 2. N Engl J Med. (2009) 361:358-67. doi: 10.1056/NEJMoa0902579

68. Blakeley JO, Ye X, Duda DG, Halpin CF, Bergner AL, Muzikansky A, et al. Efficacy and biomarker study of bevacizumab for hearing loss resulting from neurofibromatosis type 2-associated vestibular schwannomas. J Clin Oncol. (2016) 34:1669-75. doi: 10.1200/jco.2015.64.3817

69. Wong HK, Lahdenranta J, Kamoun WS, Chan AW, McClatchey AI, Plotkin SR, et al. Anti-vascular endothelial growth factor therapies as a novel therapeutic approach to treating neurofibromatosis-related tumors. Cancer Res. (2010) 70:3483-93. doi: 10.1158/0008-5472.Can-09-3107

70. Huang V, Bergner AL, Halpin C, Merker VL, Sheridan MR, Widemann $\mathrm{BC}$, et al. Improvement in patient-reported hearing after treatment with bevacizumab in people with neurofibromatosis type 2. Otol Neurotol. (2018) 39:632-8. doi: 10.1097/mao.0000000000001781

71. Lassaletta L, Torres-Martin M, Pena-Granero C, Roda JM, Santa-CruzRuiz S, Castresana JS, et al. NF2 genetic alterations in sporadic vestibular schwannomas: clinical implications. Otol Neurotol. (2013) 34:1355-61. doi: 10.1097/MAO.0b013e318298ac79

72. Selvanathan SK, Shenton A, Ferner R, Wallace AJ, Huson SM, Ramsden RT, et al. Further genotype-phenotype correlations in neurofibromatosis 2. Clin Genet. (2010) 77:163-70. doi: 10.1111/j.1399-0004.2009. 01315.x

73. Halliday D, Emmanouil B, Pretorius P, MacKeith S, Painter S, Tomkins H, et al. Genetic Severity Score predicts clinical phenotype in NF2. J Med Genet. (2017) 54:657-64. doi: 10.1136/jmedgenet-2017104519

74. Emmanouil B, Houston R, May A, Ramsden JD, Hanemann CO, Halliday $\mathrm{D}$, et al. Progression of hearing loss in neurofibromatosis type 2 according to genetic severity. Laryngoscope. (2019) 129:974-80. doi: 10.1002/lary.2 7586

Conflict of Interest Statement: The authors declare that the research was conducted in the absence of any commercial or financial relationships that could be construed as a potential conflict of interest.

Copyright (C) 2019 Lassaletta, Calvino, Morales-Puebla, Lapunzina, Rodriguez-de la Rosa, Varela-Nieto and Martinez-Glez. This is an open-access article distributed under the terms of the Creative Commons Attribution License (CC BY). The use, distribution or reproduction in other forums is permitted, provided the original author(s) and the copyright owner(s) are credited and that the original publication in this journal is cited, in accordance with accepted academic practice. No use, distribution or reproduction is permitted which does not comply with these terms. 